\begin{tabular}{c|c|c} 
ISSN 2525-4812 (versão online) & Recebido em: 31/5/2020 & Revista Terceira \\
ISSN 2238-7641 (versão impressa) & Aprovado para Sober 2020: 23/7/2020 & Margem Amazônia \\
http://www.revistaterceiramargem.com/ & Aceito para RTMA: 20/3/2021 & Pán \\
index.php/terceiramargem/index & Período de publicação: jan./jul. 2021 & (v. 7 • n. 17 • Jan./Jun. 2021) \\
\hline
\end{tabular}

Como citar o artigo:

MARCONATO, M.; DAL MORO, O. F.; MICHELLON, E. Análise do desenvolvimento multidimensional na área rural dos estados brasileiros nos anos de 2005 e 2015. Revista Terceira Margem Amazônia, v. 7, n. 17, p. 9-32, 2021. DOI: http://dx.doi. org/10.36882/2525-4812.2021v7i17.p9-32

\title{
ANÁLISE DO DESENVOLVIMENTO MULTIDIMENSIONAL NA ÁREA RURAL DOS ESTADOS BRASILEIROS NOS ANOS DE 2005 E 2015
}

\author{
Márcio Marconato \\ Odirlei Fernando Dal Moro ${ }^{2}$ \\ Ednaldo Michellon ${ }^{3}$
}

\begin{abstract}
Resumo: Estudar o desenvolvimento socioeconômico de um país, estado ou município é conhecer as condições de vida da sua população. Assim, o objetivo deste estudo é construir um indicador que mostre as condições socioeconômicas da população rural nos estados brasileiros nos anos de 2005 e 2015. Para tanto foi utilizada como metodologia a análise fatorial e o Índice Bruto de Desenvolvimento (IDB). As variáveis selecionadas representam os aspectos de renda, educação, saúde, acesso a bens duráveis e infraestrutura domiciliar. Os resultados mostraram que, no ano de 2005, havia nove estados que eram considerados de elevado desenvolvimento. Em 2015, esse número subiu para 16, representando mais de $50 \%$ das unidades federativas do Brasil. Na outra ponta, a quantidade de estados que eram considerados de baixo desenvolvimento passou de oito em 2005 para três em 2015, o que indica uma melhora na vida da população rural. O estudo concluiu que houve avanços nas condições de vida da população rural nos estados, sobretudo no acesso a bens duráveis e infraestrutura domiciliar. Entretanto, é visível que as políticas públicas voltadas à melhoria das condições de vida dos cidadãos na área rural devem continuar, e novas devem surgir, a fim de minimizar as disparidades sociais e econômicas entre as regiões do Brasil, uma vez que a maioria dos estados considerados de elevado desenvolvimento está localizada nas regiões Sul e Sudeste.
\end{abstract}

Palavras-chave: desenvolvimento econômico, análise fatorial, pobreza rural, desenvolvimento rural.

\footnotetext{
${ }_{1}$ Economista, doutor em Economia, professor colaborador da Universidade Estadual de Ponta Grossa (UEPG), Ponta Grossa, PR.

E-mail: marconatoce@bol.com.br

(D) https://orcid.org/0000-0001-9198-7610

2 Economista, doutor em Teoria Econômica, professor do Departamento de Administração da Universidade Federal do Mato Grosso do Sul (UFMS), Paranaíba, MS.

E-mail: odirlei.moro@ufms.br

(i) https://orcid.org/0000-0003-3376-9003

3 Engenheiro-agrônomo, doutor em Ciências Econômicas, professor do Departamento de Economia da Universidade Estadual de Maringá (UEM), Maringá, PR.

E-mail: emichellon@uem.br

(D) https://orcid.org/0000-0002-8877-4769
} 


\title{
ANALYSIS OF MULTIDIMENSIONAL DEVELOPMENT IN THE RURAL AREA OF BRAZILIAN STATES IN THE YEARS OF 2005 AND 2015
}

\begin{abstract}
To study socioeconomic development in a country, state or municipality is to know the living conditions of its population. Thus, the objective of the present study is to build an indicator that shows the socioeconomic conditions of the rural population in the Brazilian states in the years 2005 and 2015. For this purpose, the factor analysis and the Gross Development Index (IDB) used as methodology. The selected variables represent aspects of income, education, health, access to durable goods and home infrastructure. The results show $\mathrm{r} \mathrm{m}$ that in 2005; there were nine states that considered to be highly developed. In 2015 , that number rose to 16 , representing more than $50 \%$ of the federative units in Brazil. On the other hand, the number of states that were considered to be of low development went from eight in 2005 to three in 2015, which indicates an improvement in the life of the rural population. The study concluded that there were advances in the living conditions of the rural population in the states, especially in access to durable goods and home infrastructure. However, it is visible that public policies aimed at improving the living conditions of citizens in the rural area must continue and new ones should emerge, in order to minimize the social and economic disparities between the regions of Brazil, since most of the states considered high development are located in the South and Southeast regions.
\end{abstract}

Keywords: economic development, factor analysis, rural poverty, rural development.

\section{Introdução}

As condições sociais e econômicas da população têm sido foco do debate de vários estudos, sendo que as informações e resultados por eles produzidos vêm auxiliando na formulação de políticas públicas para a melhoria das condições de vida da população brasileira. A pobreza é marcante na sociedade e atinge uma quantidade significativa de pessoas, especialmente no meio rural. Nos meios urbanos, as condições no mercado de trabalho e na educação são melhores, o que possibilita rendas maiores e consequentemente a superação da miséria. No que tange às condições de vida dos cidadãos que residem na área rural, os estudos devem verificar quais são os problemas que afligem a grande parte da população, no intuito de que ações sociais do estado sejam direcionadas sobretudo a essa população.

Em tal contexto, a Constituição Brasileira de 1988 estabelece várias obrigações aos gestores públicos junto à população quanto aos serviços de educação, saúde, segurança pública, infraestrutura urbana, geração de emprego e renda, cuidados com o meio ambiente, entre outros. No que concerne ao meio rural, Grisa e Schneider (2015) reforçam que a Constituição de 1988 incitou novos espaços de participação social e reconheceu direitos voltados aos moradores das áreas rurais. A criação do Programa Nacional de Fortalecimento da Agricultura (Pronaf), em 1995, a criação do Ministério do Desenvolvimento Agrário (MDA), em 1999, da Secretaria da Agricultura Familiar (SAF), em 2001, e a regulamentação da Lei da Agricultura Familiar, em 2006, são alguns exemplos de que o Estado passou a reconhecer mais essa categoria social e consequentemente a balizar as políticas públicas focadas nesse grupo social.

Os dados do Instituto Brasileiro de Geografia e Estatística (IBGE, 2015) reforçam as evidências a favor das populações residentes no meio urbano. Enquanto $93 \%$ da população na área urbana tinha água com canalização interna no ano de 2015, na área rural eram apenas 31\%. O acesso a esgotamento sanitário era ainda pior, haja vista que na área urbana $66 \%$ tinham acesso a 
saneamento básico, enquanto no meio rural não atingia 6\%, em 2015. As disparidades se revelam em outros indicadores quando mensurado o acesso a bens duráveis, educação, saúde, entre outros.

Diante disso, o objetivo do presente estudo é construir um indicador que mostre as condições socioeconômicas da população rural nos estados brasileiros nos anos de 2005 e 2015. Para atender o objetivo deste estudo foram selecionadas 15 variáveis que representam a renda, a educação da população e dos trabalhadores, uma proxy para saúde, o percentual da população que possui acesso a bens duráveis e percentual de pessoas que moram em residências que possuem infraestrutura básica. O procedimento metodológico consiste na aplicação da análise fatorial, na sequência é calculado o índice bruto (IB) e pelo processo de interpolação é criado o Índice de Desenvolvimento Rural (IDR). O intuito principal é mostrar quais são os estados que possuem os melhores e piores indicadores de qualidade de vida da população rural em 2005 e 2015.

A justificativa que norteia a decisão pela abordagem da temática do desenvolvimento rural assenta-se na necessidade de contribuir com o tema, produzindo conhecimento capaz de direcionar as políticas públicas de desenvolvimento rural, especialmente no Brasil, um País caracterizado pela desigualdade social, que é mais visível no meio rural, ainda que no meio urbano sua presença também seja representativa. Além do mais, trata-se de uma oportunidade de oferecer conhecimento a respeito das necessidades ainda vivenciadas pelos cidadãos que residem no meio rural, dando uma pequena contribuição para o debate.

Para atender os objetivos propostos, o presente estudo está dividido em quatro seções além desta introdução e das considerações finais. Na primeira seção é abordada a evolução do conceito de desenvolvimento socioeconômico e são apresentados alguns estudos que focaram no desenvolvimento regional e municipal no Brasil. Na segunda seção são apresentados as variáveis, a fonte dos dados e o procedimento metodológico utilizado. Na terceira, por fim, estão os resultados e discussões sobre as principais evidências encontradas.

\section{Referencial teórico e empírico}

O conceito de desenvolvimento apresentou mudanças significativas ao longo do tempo. A partir do final da Segunda Guerra Mundial até o início dos anos 1970, o crescimento econômico era compreendido por grande parte da literatura econômica como sinônimo de desenvolvimento, tendo-se na industrialização sua base principal (DIAS, 2011). Posteriormente, passou-se gradativamente a reconhecer que o crescimento do Produto Interno Bruto (PIB) era um dos elementos que contribuíam para melhorar o nível de desenvolvimento de um país, mas que, além disso, deveria haver uma melhora nas condições de vida dos cidadãos, ou seja, o crescimento era necessário mas não suficiente. Com base nisso, Colman e Nixson (1981) argumentam que o desenvolvimento é um processo de aperfeiçoamento que envolve um conjunto de valores relacionados às condições desejáveis pela sociedade.

A partir de então, novas discussões surgiram para fazer frente aos anseios de um novo modo de conceituar e mensurar o desenvolvimento socioeconômico, que foi medido por vários anos pela renda nacional, principalmente pelo PIB per capita. Sobre esse aspecto, Mankiw (2016) reforça que utilizar o PIB como medida de desenvolvimento pode ser limitado. O autor destaca que o PIB pode não representar bem os indicadores de bem-estar social, mas lembra que a riqueza 
econômica permite investir em educação, saúde e políticas de emprego, que consequentemente vão ajudar a melhorar a vida das pessoas na sociedade.

No mesmo sentido de análise, Sen (2000) destaca que o crescimento do produto do país é um importante meio de expandir as liberdades desfrutadas pelos membros da sociedade. Mas as liberdades, por sua vez, dependem de outros fatores, como disposições sociais e econômicas, que reforçam uma abordagem multidimensional para a análise do tema.

A partir da evolução da concepção de desenvolvimento econômico, a medida clássica de crescimento passou a ser criticada por três motivos: 1) por não incorporar a questão da distribuição da renda interna; 2) por não considerar que a variação cambial das diversas moedas nacionais também é um fator relevante; e 3) por considerar o tema apenas do ponto de vista unidimensional, não captando outros aspectos importantes do desenvolvimento, tais como educação, saúde e meio ambiente. Por essas razões, surgiu a necessidade de encontrar uma medida que melhor representasse o nível de bem-estar da população (CARDOSO; RIBEIRO, 2015).

Assim, o conceito de desenvolvimento passou a abranger outras variáveis além da renda per capita, como educação, saúde, infraestrutura urbana, etc. Nesse sentido, iniciaram-se os trabalhos para a criação de indicadores de desenvolvimento multidimensional que incluíssem diversas variáveis capazes de representar as condições de vida da sociedade. Um desses esforços culminou na criação do Índice de Desenvolvimento Humano (IDH), criado por Amartya Sen e Mahbubul Haq, na década de 1990 (IPEA, 2013). De acordo com Jorge et al. (2010), o IDH passou a ser o indicador mais utilizado do mundo, pois procurava refletir, além da renda, duas características desejadas e esperadas do desenvolvimento humano: a longevidade da população, expressa pela esperança de vida ao nascer; e o grau de maturidade educacional, avaliado pela taxa de alfabetização de adultos e pela taxa combinada de matrícula nos três níveis de ensino.

Logo, por englobar poucas variáveis, o IDH passou a ser criticado, uma vez que mensura o comportamento das variáveis para os países, mas não considera as diferenças regionais, tão presentes, por exemplo, no Brasil. Uma das soluções para isso foi a compilação de dados estaduais e municipais para a construção de indicadores que revelassem a situação econômica e social em diferentes períodos, destacando-se, assim, os avanços observados e as disparidades regionais. Um desses indicadores é o da Federação das Indústrias do Rio de Janeiro (Firjan), que passou a calcular o Índice Firjan de Desenvolvimento Municipal (IFDM), de abrangência nacional (FIRJAN, 2016).

No âmbito regional, entre os indicadores que refletem a condição de vida da população nos municípios, pode ser destacado o Índice Ipardes de Desenvolvimento Municipal (IPDM), o Índice de Desenvolvimento Econômico (IDE) e o Índice de Desenvolvimento Socioeconômico (Idese). O IPDM é calculado pelo Instituto Paranaense de Desenvolvimento Econômico e Social (Ipardes) e abrange três dimensões: renda, educação e saúde (IPARDES, 2016).

O Índice de Desenvolvimento Econômico (IDE), por sua vez, é calculado pela Superintendência de Estudos Econômicos e Sociais da Bahia (SEI) e busca refletir as condições sociais e econômicas nos municípios baianos. $\mathrm{O}$ indicador é composto por variáveis como infraestrutura, mão de obra e produto municipal (SEI, 2020). Por sua vez, o Idese é calculado pela 
Fundação de Economia e Estatística do Rio Grande do Sul (FEE) e é composto por 12 variáveis divididas em quatro temáticas: educação, renda, saneamento, domicílios e saúde (FEE, 2020).

Conforme salientam Oliveira e Silva (2012), a avaliação e o monitoramento das condições do desenvolvimento socioeconômico nos municípios brasileiros não são tarefas fáceis, dada a existência de significativas diferenças entre as regiões do País. Essas disparidades regionais vão além de condições econômicas e sociais, incluindo também fatores culturais e até mesmo ambientais.

Nesse sentido, vários estudos passaram a ser realizados aplicando-se a análise fatorial para criar indicadores que demonstrassem as condições de vida da população. Procurando desenvolver um indicador para analisar o índice de desenvolvimento dos municípios mineiros, Cardoso e Ribeiro (2015) construíram o Índice Relativo de Qualidade de Vida (IRQV) utilizando dados referentes ao ano de 2010. Após calcular o índice, os autores realizaram a hierarquização para verificar quanto um município é mais ou é menos desenvolvido segundo o nível de qualidade de vida. O procedimento metodológico para a construção do IRQV foi a análise fatorial. Os resultados indicaram o município de Belo Horizonte como o mais desenvolvido em relação aos demais; e, no extremo oposto, o município de São João das Missões. O trabalho também identificou que os municípios situados ao norte do estado são menos desenvolvidos, enquanto os do sul apresentam melhores níveis socioeconômicos.

Para analisar o desenvolvimento municipal paranaense, Lima et al. (2014) utilizaram o IFDM referente aos anos de 2000, 2005 e 2010. A metodologia empregada foi a Análise Exploratória de Dados Espaciais (Aede) para verificar a existência de autocorrelação espacial e a formação de clusters de desenvolvimento entre os seus municípios. O índice agregado e os indicadores desemprego e renda, educação e saúde mostraram que o desenvolvimento, para a maioria dos municípios paranaenses, melhorou, tanto para o índice geral como para os índices de emprego e renda, educação e saúde. No que tange à análise espacial dos dados, constatou-se a existência de autocorrelação espacial positiva para todos os anos estudados. Os clusters de desenvolvimento se distribuíram basicamente em três mesorregiões: norte central, oeste e metropolitana de Curitiba, e os clusters de subdesenvolvimento se distribuíram na região central e leste do estado.

Com intuito de verificar a evolução das condições de vida da população dos municípios brasileiros, Marconato e Cunha (2016) criaram um indicador multidimensional para estudar o desenvolvimento nos municípios brasileiros e compararam sua evolução entre os anos de 2000 e 2010. Para tanto utilizaram como metodologia a análise fatorial e de cluster. Os resultados mostraram que grande parte dos municípios localizados nas regiões Norte e Nordeste estava concentrada em clusters considerados de baixo desenvolvimento no ano de 2000. No entanto, em 2010, houve uma melhora significativa nos indicadores socioeconômicos, e muitos dos municípios apareceram nos agrupamentos de melhor desenvolvimento econômico. Assim, o estudo conclui que, ao longo de uma década, os municípios com menores índices de desenvolvimento apresentaram significativa melhoria na qualidade de vida da sua população, porém os esforços do poder público para elaborar políticas de emprego e de combate à violência em diversos municípios brasileiros devem ser constantes, pois auxiliam na melhora dos indicadores socioeconômicos. 
No que diz respeito ao âmbito rural, também foram realizados estudos com o intuito de identificar as condições sociais e econômicas da população. Nesse aspecto, o trabalho realizado por Hoffmann e Kageyama (1985) analisou a relação entre modernização da agropecuária e a desigualdade de renda no Brasil nos anos de 1975 e 1980. Os autores utilizaram a análise fatorial para transformar as 29 variáveis selecionadas em um indicador que representava a modernização tecnológica da agricultura dos estados brasileiros. Além do mais, selecionaram um indicador de pobreza e de concentração de renda. Os resultados obtidos revelaram associação positiva entre o índice de modernidade e entre a renda per capita, assim também com relação à desigualdade de renda. No que se refere a pobreza e índice de modernização, observou-se relação negativa.

Ao tratar do tema, Del Grossi (1999) observou que a população rural não é exclusivamente agrícola, já que mais de 3,9 milhões de pessoas estavam ocupadas em atividades não agrícolas em 1995, o que representava 26\% da PEA rural ocupada da época. De acordo com o autor, a PEA rural não agrícola, de certa forma, vem mantendo o contingente de trabalhadores rurais, pois, enquanto os ocupados na agricultura permaneceram estagnados entre 1981 e 1995, ela aumentou em quase 1 milhão de pessoas em todo o País, principalmente nas regiões Sudeste e Centro-Oeste.

O estudo realizado por Melo e Parré (2007) objetivou construir um indicador de desenvolvimento rural para o estado do Paraná, procurando hierarquizar e identificar os fatores determinantes que contribuem para melhorar as condições sociais e econômicas. Ao utilizar a análise fatorial e 18 variáveis, os autores construíram um índice para observar o nível de desenvolvimento municipal. Os resultados mostraram que, numa escala de zero a cem, o índice médio de desenvolvimento rural situou-se em 43,63, resultando num total de 179 municípios $(44,86 \%)$ acima desse valor e 220 municípios $(55,14 \%)$ abaixo desse índice. A ordenação de acordo com o grau de desenvolvimento evidenciou que mais da metade dos municípios se situam nos níveis de desenvolvimento rural baixo, sugerindo a necessidade de medidas para minimizar os efeitos gerados pelos aspectos que devem ser trabalhados de forma mais intensa, visando melhorar a vida no campo e, por conseguinte, a situação dos municípios.

Para avaliar as condições da população rural nas microrregiões do Brasil, Stege e Parré (2013) utilizaram a análise fatorial e calcularam o IDR com base nos dados de 2006 e de 2008. Os resultados apontaram um desenvolvimento rural bastante heterogêneo nas microrregiões e um processo de desenvolvimento rural que vai além da análise do crescimento econômico medido pelo produto e pela renda per capita, uma vez que foram encontrados fatores relacionados ao bem-estar dos domicílios rurais, meio ambiente, sistema educacional, entre outros.

Posteriormente, Rodrigues (2014), utilizando a análise fatorial, estudou os estados brasileiros destacando as condições nos meios rural e urbano. O referido trabalho contribuiu para a caracterização dos espaços urbanos e rurais no Brasil. Os resultados indicaram haver 1.385 municípios brasileiros, distribuídos em praticamente todas as regiões, porém com maior incidência nas regiões Centro-Oeste, Sudeste e Sul, nos quais predomina o setor agropecuário na formação do PIB e na oferta de emprego. Esses municípios continuam a ter na agropecuária a sua maior fonte de riqueza, representando $35 \%$ do PIB e 47,62\% da ocupação.

O estudo desenvolvido por Pinto et al. (2018) procurou apresentar o Índice de Desenvolvimento Humano Rural (IDHM Rural) com o intuito de refletir as condições sociais das 
pessoas e das famílias no espaço rural brasileiro objetivando observar os avanços e os efeitos das políticas que estavam sendo executadas e captar as novas sutilezas que se impõem, decorrentes das conjunturas socioeconômicas. Os autores utilizaram os dados do Censo de 2010 do IBGE e apresentaram as condições rurais para os estados brasileiros. Os resultados mostraram que os indicadores de renda e educação rural ficaram abaixo do observado para o índice geral, sugerindo a necessidade de estabelecimento de melhores condições de renda, níveis educacionais nas áreas rurais.

Um estudo da literatura internacional, tendo como ponto de análise a relevância das obras ao tema aqui proposto, ao número de citações na plataforma Scopus, observou uma diversidade de contribuições a respeito do tema pobreza rural. Bebbington (1999) oferece uma análise sobre a viabilidade camponesa, os meios de subsistência e a pobreza rural. Para o autor, proporcionar às famílias rurais meios para a subsistência é uma forma de garantir a sustentabilidade e o desenvolvimento rural, sendo o acesso a máquinas e equipamentos uma das formas concretas para o desenvolvimento sustentável. Lamb et al. (2005), por sua vez, destacam que a incidência da pobreza rural possui relação com a presença de grandes áreas degradadas, especialmente nas regiões de clima tropical. De modo conclusivo, os autores comentam que desestimular a degradação ambiental e motivar o reflorestamento são formas diretas de minimização da pobreza rural.

Ravallion e Datt (1999), na tentativa de mostrarem como alguns estados da Índia conseguiram reduzir a pobreza rural mais que outros, concluíram que a pobreza rural está diretamente associada à infraestrutura rural (máquinas, equipamentos, instalações, etc.) e ao capital humano. Em outras palavras, a redução da pobreza rural depende da combinação entre capital físico, incluso em tal contexto o acesso ao crédito, e capital humano, relativo ao conhecimento ou à experiência com as atividades rurais. Glaser (2005), em um estudo específico sobre o ecossistema de mangue na região do estuário de Caeté, Norte do Brasil, mostrou que o baixo capital humano, as ocupações em trabalhos de baixa remuneração, pequena assistência médica, dificuldade de acesso à eletricidade e ao baixo valor agregado dos produtos vendidos são fatores determinantes para a incidência da pobreza rural na região.

Batista e Neder (2014), utilizando a metodologia de painéis dinâmicos, mostraram que a combinação entre crescimento e desconcentração da renda per capita rural é decisiva para a diminuição da pobreza rural. Ademais, o governo brasileiro tem papel preponderante nesse processo, sendo os programas nacionais de estímulo à agricultura familiar um dos mecanismos. Nascimento (2007) afirma que o aumento de famílias rurais atuando em atividades agrícolas diversificadas e o estímulo à produção agrícola em pequenas propriedades são cada vez mais aceitos na literatura como argumentos favoráveis à redução da pobreza rural.

Mattos e Santos (2017) analisaram a dinâmica da pobreza rural da região Nordeste do Brasil entre 1995 e 2012 e observaram que a redução dela esteve associada a melhora nas condições de moradia, bens domésticos, acesso à educação, emprego e renda. Em outro trabalho, Mattos e Bagolin (2017) mostraram que os programas sociais tiveram um papel preponderante na minimização da pobreza rural. 


\section{Metodologia}

\section{Dados e sua fonte}

Os dados utilizados no presente trabalho estão disponíveis na Pesquisa Nacional por Amostra de Domicílios (PNAD), divulgada pelo IBGE, referente aos anos de 2005 e 2015 (IBGE, 2015). As variáveis refletem o nível de desenvolvimento dos estados no tocante a emprego, renda, educação, saúde, condição de infraestrutura domiciliar e acesso a bens duráveis. Abaixo são elencadas e explicadas as variáveis observadas por este estudo.

- A renda é um dos elementos imprescindíveis para que as pessoas possam adquirir bens e serviços. Assim, a variável "Percentual de pessoas com 10 anos ou mais na área rural que recebem o valor de um salário mínimo ou menos (RR)" procura mensurar a proporção de pessoas que vivem com limitação de renda na área rural.

- A educação é outro fator que impacta a qualidade de vida dos cidadãos. Em tal ponto, foi incluída na análise a variável "Percentual de pessoas com 10 anos ou mais e que são analfabetas (ANALF)", a qual procura mensurar o percentual de pessoas em diversos estratos de idade que, por uma razão ou outra, não tiveram acesso adequado à educação.

- Ainda dentro do tema educação, considerou-se a variável "Nível educacional dos trabalhadores de 10 anos ou mais na área rural (NETR)", sendo que essa variável considera o percentual de trabalhadores no meio rural que possuíam de 8 a 14 anos de estudo.

- Para reforçar a percepção sobre as condições no mercado de trabalho no meio rural foi incluída na análise a variável "Percentual de pessoas ocupadas (PO)", que inclui o percentual de pessoas consideradas ocupadas com 15 anos de idade ou mais, no total de pessoas na referida faixa de idade.

- A saúde é outro item de suma importância para avaliar o desenvolvimento de uma população, sendo assim, foi considerada a variável "Percentual de mulheres com 15 anos ou mais no meio rural cujos filhos nasceram mortos (PMFM)", sendo que essa variável foi incluída na análise como proxy para o indicador de saúde.

- A possibilidade de comprar bens duráveis indica se as pessoas estão obtendo trabalho e renda suficientes para comprar alguns bens essenciais, como fogão, geladeira, máquina de lavar roupa, freezer, televisão e telefone. Assim, a variável "Possui Fogão (PF)" representa o percentual de pessoas na área rural que residem em moradia com fogão.

- A variável "Possui Geladeira (PG)" representa o percentual de pessoas na área rural em moradias com geladeira.

- A variável “Possui Máquina de Lavar Roupa (PMLR)" procura demostrar o percentual de pessoas no meio rural que residem em moradia com máquina de lavar roupa.

- A variável "Possui Televisão (PT)" representa o percentual de pessoas na área rural que residem em moradia com televisão. 
- A variável "Possui Freezer (PFR)" representa o percentual de pessoas na área rural que residem em moradia com freezer.

- A variável "Possui Telefone (PTEL)" representa o percentual de pessoas na área rural que residem em moradia com telefone.

Para mensurar as condições de vida, no que se refere à infraestrutura urbana, foram selecionadas quatro variáveis: acesso a água encanada, acesso a algum tipo de saneamento, acesso a coleta de lixo e se possui acesso a energia elétrica.

- Primeiramente, a variável “Acesso a Água Encanada (AAE)" representa o percentual de pessoas na área rural que residem em residências com canalização de água interna.

- Em segundo lugar, tem-se a variável “Acesso a Saneamento Básico (ASB)”, que representa o percentual de pessoas na área rural que moram em residência onde há esgotamento sanitário (rede de coleta ou fossa séptica).

- Em terceiro lugar, tem-se a variável "Acesso a Coleta de Lixo (ACL)", que representa o percentual de pessoas na área rural que habitam residências onde o lixo é coletado direta e indiretamente.

- Em quarto lugar, tem-se a variável “Acesso a Energia Elétrica (AEE)”, que mensura o percentual de pessoas no meio rural que habitam residência onde há energia elétrica.

$\mathrm{Na}$ Tabela 1 estão apresentadas as variáveis utilizadas na pesquisa, assim como seus referidos percentuais, para os anos de 2005 e 2015. Por causa da relevância, as variáveis apontadas podem ser consideradas como indicadores de desenvolvimento econômico nas áreas rurais.

Tabela 1. Indicadores de desenvolvimento rural no Brasil em 2005 e 2015 (\%).

\begin{tabular}{|c|c|c|c|}
\hline Variável & Descrição & 2005 & 2015 \\
\hline RR & Percentual de pessoas (idade $\geq 10$ anos) que ganham um salário mínimo ou menos & 7,7 & 8,0 \\
\hline ANALF & Percentual da população rural (idade $\geq 5$ anos) que são analfabetas & 6,0 & 4,0 \\
\hline NETR & Percentual de trabalhadores (idade $\geq 10$ anos) na área rural com 8 a 14 anos de estudo & 21,3 & 35,6 \\
\hline $\mathrm{PO}$ & Percentual de pessoas (idade $\geq 15$ anos) ocupadas & 68,2 & 56,3 \\
\hline PMFM & Percentual de mulheres (idade $\geq 15$ anos) no meio rural cujos filhos nasceram mortos & 0,5 & 0,4 \\
\hline $\mathrm{PF}$ & Percentual de pessoas na área rural em moradia que possui fogão & 93,0 & 97,1 \\
\hline PG & Percentual de pessoas na área rural em moradia com geladeira & 63,3 & 90,5 \\
\hline PMLR & Percentual de pessoas na área rural em moradia com máquina de lavar roupa & 10,4 & 33,5 \\
\hline PT & Percentual de pessoas na área rural em moradia que possui televisão & 71,6 & 93,2 \\
\hline PFR & Percentual de pessoas na área rural em moradia que possui freezer & 19,4 & 29,9 \\
\hline PTEL & Percentual de pessoas na área rural em moradia que possui telefone & 34,6 & 80,9 \\
\hline AAE & Percentual de pessoas na área rural em residência com água potável & 59,5 & 77,0 \\
\hline ASB & Percentual de pessoas na área rural em residência com saneamento básico & 19,3 & 4,8 \\
\hline $\mathrm{ACL}$ & Percentual de pessoas na área rural em residência com coleta de lixo & 23,6 & 34,0 \\
\hline AEE & Percentual de pessoas na área rural em residência com energia elétrica & 82,5 & 97,5 \\
\hline
\end{tabular}

Fonte: Elaborado pelos autores com base em dados do IBGE $(2005,2015)$. 
A primeira variável é o percentual de pessoas com renda igual ou inferior ao salário mínimo, na qual se observou relativa estabilidade em 2015 (8\%), quando comparado a 2005 (7,7\%). Por outro lado, no que diz respeito às variáveis educacionais, observaram-se: 1) uma diminuição do percentual de analfabetos, passando de 6,0\%, em 2005, para 4,0\%, em 2015; e 2) um aumento do percentual de trabalhadores que possuíam entre 8 e 14 anos de estudo, saindo de 21,3\%, em 2005, para 35,6\%, em 2015 (Tabela 1).

Sobre o mercado de trabalho na área rural observou-se que o percentual de ocupados diminuiu entre os 2 anos analisados, passando de 68,2\%, em 2005, para 56,3\%, em 2015. Esse resultado possivelmente pode estar associado à crise econômica vivenciada pelo Brasil em 2015, quando o País registrou uma retração de 3,5\% do PIB, a maior queda desde 1990, com reflexos diretos sobre o mercado de trabalho (IBGE, 2019). Pelo lado da saúde, a proxy que mede a saúde no meio rural nos estados brasileiros, representada pelo percentual de mulheres grávidas cujos filhos nasceram mortos, diminuiu de $0,5 \%$, em 2005 , para $0,4 \%$, em 2015 , sugerindo uma pequena melhora.

Na sequência estão as variáveis que representam o acesso a bens duráveis e a infraestrutura básica dos moradores no meio rural. Os resultados da pesquisa mostram que houve um avanço em todos os bens duráveis selecionados e em três das áreas ligadas a infraestrutura, com exceção do saneamento básico. No que se refere ao acesso a bens duráveis, verificou-se que, em 2005, cerca de 93,0\% das pessoas moravam em residências com fogão. Em 2015 o percentual subiu para $97,0 \%$.

No que diz respeito a possuir ou não geladeira, o crescimento foi muito expressivo, saindo de $63,3 \%$, em 2005, para 90,5\%, em 2015. Embora possa parecer uma variável banal, ela reflete outras questões importantes previamente atendidas, como o acesso à energia elétrica e melhor possibilidade de aquisição de alimentos e conservação, possibilitando uma vida mais digna.

Sob outro aspecto, tem-se o percentual de pessoas que residiam em moradias com máquina de lavar roupa. Nesse item também houve avanços, passando de 10,4\%, em 2005, para 33,5\%, em 2015. O percentual de pessoas que possuíam televisão no domicílio rural, por sua vez, passou de 71,6\%, em 2005, para 93,2\%, em 2015. O referido item foi um dos bens duráveis mais demandados pelas famílias no período analisado, possivelmente influenciado pelo aumento da renda e do maior acesso ao crédito. Já o percentual de pessoas na área rural que possuíam freezer passou de $19,4 \%$, em 2005, para 29,9\%, em 2015. O item telefone foi um dos bens adquiridos que mais cresceu entre as famílias no meio rural. Em 2005, apenas 34,6\% da população rural possuíam telefone, atingindo 80,9\%, em 2015.

O crescimento no número de pessoas que possuem bens duráveis pode estar associado ao crescimento do consumo que ocorreu durante o governo Lula (2003-2010), impulsionado por aumento do crédito, diminuição do desemprego, aumento da renda, entre outros. Sobre essa percepção, Sicsú (2019) afirma que o consumo das famílias cresceu no período Lula, mas pode ser considerado como o motor de partida para que a economia alcançasse uma condição virtuosa de ampliação dos investimentos e redução drástica do desemprego. O autor reforça que os investimentos cresceram acima do consumo das famílias no período. 
Além das variáveis destacadas, têm-se aquelas relacionadas à infraestrutura rural. Em tal contexto, o percentual de moradores com acesso a água passou de 59,5\%, em 2005, para 77,0\%, em 2015, representando um avanço significativo, embora o ideal para o referido indicador seja próximo dos $100 \%$. Por outro lado, o percentual de pessoas em moradias com acesso a saneamento básico diminuiu de 19,3\%, em 2005, para 4,8\%, em 2015. Essa redução pode estar associada ao fato de as áreas rurais, que tinham acesso a rede de esgoto em 2005, terem sido incorporadas à área urbana ao longo do período, haja vista que quanto mais próximo das cidades, maior a possibilidade de acesso à rede de esgoto pelas propriedades rurais (IBGE, 2015) ${ }^{4}$. Sobre esse tema, Borja (2014) destacou os esforços por parte do governo federal para ampliar o acesso ao saneamento, mas a autora reforça que ainda existem muitos desafios a serem superados para universalizar o serviço a toda a população, os quais exigem a atuação coordenada das três esferas de governo.

No que diz respeito às residências rurais com coleta de lixo, observou-se que, em 2005, apenas $23,6 \%$ da população rural tinha acesso a esse serviço, subindo para 34,0\%, em 2015, demonstrando um crescimento significativo, porém em um patamar ainda muito abaixo do desejado $^{5}$. Por último é possível verificar que o percentual de pessoas residindo em moradias com acesso a energia elétrica passou de 82,5\%, em 2005, para 97,5\%, em 2015.

\section{Procedimento metodológico}

Para analisar os indicadores de desenvolvimento socioeconômico na área rural dos estados brasileiros utilizou-se o método de análise fatorial e calculou-se o índice bruto de desenvolvimento rural por meio dos escores fatoriais. O principal objetivo da análise fatorial é descrever, se possível, as relações de covariância entre muitas variáveis em termos de apenas alguns fatores, pressupondo que as variáveis podem ser agrupadas por suas correlações. Desse modo, as variáveis, dentro de um grupo particular, são altamente correlacionadas entre si, mas têm correlações relativamente pequenas com as variáveis de um grupo diferente. Então, cada grupo de variáveis representa um fator, que é responsável pelas correlações observadas (JONHSON; WICHERN, 2007).

Para Corrar et al. (2012), a análise fatorial é uma técnica estatística que permite descrever um conjunto de variáveis originais por meio da criação de menores dimensões ou fatores. $\mathrm{O}$ método pressupõe que altas correlações entre variáveis geram agrupamentos que configuram os fatores, simplificando estruturas complexas e permitindo melhor entendimento dos dados.

Entretanto, para utilizar a análise fatorial, Hair et al. (2009) destacam que é necessário seguir estes passos: formulação do problema, construção da matriz de correlação, determinação do método de análise fatorial, determinação do número de rotação dos fatores, interpretação dos fatores, cálculo das cargas fatoriais ou escolha de variáveis substitutas e determinação do ajuste do modelo. O modelo matemático que representa a análise fatorial pode ser expresso por:

\footnotetext{
${ }^{4} \mathrm{O}$ acesso a rede de esgoto nas áreas rurais, especialmente no Brasil, por causa da extensão territorial e dos custos envolvidos, mostra inviabilidade para as áreas rurais mais distantes das cidades, talvez sendo mais importante o acesso à água potável e a métodos alternativos de tratamento do esgoto. Cabe destacar que esse não é o ponto a ser tratado por este trabalho, cabendo apenas algumas observações que podem ser mais bem estudadas em futuros trabalhos.

5 Sob tal contexto, uma mudança de cultura no sentido de separação dos resíduos sólidos, por parte dos moradores das áreas rurais, para recolhimento em períodos mais espaçados parece ser uma alternativa viável, passível de melhores aprofundamentos de análise.
} 


$$
\begin{aligned}
& z_{1}=\alpha_{11} f_{1}+\alpha_{12} f_{2}+\alpha_{13} f_{3}+\ldots+\alpha_{1 m} f_{m}+\alpha_{1} \\
& z_{2}=\alpha_{21} f_{1}+\alpha_{22} f_{2}+\alpha_{23} f_{3}+\ldots+\alpha_{2 m} f_{m}+\alpha_{2} \\
& z_{3}=\alpha_{31} f_{1}+\alpha_{32} f_{2}+\alpha_{33} f_{3}+\ldots+\alpha_{3 m} f_{m}+\alpha_{3} \\
& \ldots \\
& z_{m}=\alpha_{m} f_{1}+\alpha_{m 2} f_{2}+\alpha_{m 3} f_{3}+\ldots+\alpha_{m m} f_{m}+\alpha_{m}
\end{aligned}
$$

Em notação matricial, tem-se:

$z=A f+\varepsilon$

ou ainda:

$$
\left[\begin{array}{c}
\mathbf{z}_{1} \\
\mathbf{z}_{2} \\
\mathbf{z}_{3} \\
\ldots \\
\mathbf{z}_{p}
\end{array}\right]=\left[\begin{array}{ccccc}
\alpha_{1} & \alpha_{\mathfrak{2}} & \alpha_{\mathfrak{B}} & \ldots & \alpha_{1 m} \\
\alpha_{\mathfrak{1}} & \alpha_{2} & \alpha_{3} & \ldots & \alpha_{2 m} \\
\alpha_{3} & \alpha_{3} & \alpha_{3} & \ldots & \alpha_{3 m} \\
\ldots & \ldots & \ldots & \ldots & \ldots \\
\alpha_{p 1} & \alpha_{p 2} & \alpha_{p 3} & \ldots & \alpha_{m}
\end{array}\right]\left[\begin{array}{c}
f_{1} \\
f_{2} \\
f_{3} \\
\ldots \\
f_{m}
\end{array}\right]+\left[\begin{array}{c}
\varepsilon_{1} \\
\varepsilon_{2} \\
\varepsilon_{3} \\
\ldots \\
\varepsilon_{p}
\end{array}\right]
$$

$\alpha_{i j}=$ peso carga da i-ésima variável no j-ésimo fator.

$A=$ matriz de pesos ou cargas fatoriais, mede o grau de correlação entre a variável original e os fatores.

$z=$ vetor que representa as variáveis padronizadas.

$f=$ vetor que representa os fatores comuns não correlacionados entre si.

$\varepsilon=$ vetor de erro que representa a parcela de variação de cada variável que é exclusiva dela e não pode ser explicada por um fator nem por outra variável do conjunto analisado.

O método de estimação dos fatores foi o de componentes principais, pois, de acordo com Hoffmann (1999), é o mais simples e utilizado pelos pesquisadores. De acordo com Hair et al. (2009), o método de componente principal considera a variância total e deriva fatores que contêm pequenas proporções de variância única e, em alguns casos, variância de erro. Os primeiros fatores não contêm variância de erro suficiente para distorcer a estrutura fatorial geral. Assim, o primeiro fator contém o maior percentual de explicação da variância total das variáveis da amostra. O segundo fator, por sua vez, contém o segundo maior percentual, e assim sucessivamente.

Um elemento importante na interpretação dos fatores obtidos com a análise fatorial é a sua rotação, podendo ser ortogonal ou oblíqua. Segundo Hoffmann (1999), a rotação ortogonal permite obter uma nova matriz dos coeficientes de fatores, de maneira que os valores absolutos dos elementos de cada coluna dessa matriz se aproximem de 0 ou 1. Isso facilita a interpretação dos fatores, pois cada um dos novos fatores, após a rotação, deve apresentar uma correlação relativamente forte com uma ou mais variáveis e correlação relativamente fraca com as demais variáveis.

Entre os métodos de rotação ortogonal, Hair et al. (2009) destacam que o Varimax se constitui no mais comumente utilizado e minimiza o número de variáveis com altas cargas sobre o fator, auxiliando na interpretação dos fatores. Depois da rotação e interpretação dos fatores, as 
cargas fatoriais devem ser calculadas. Cada variável possui, para cada fator encontrado, um escore fatorial. O peso ou coeficiente das cargas fatoriais pode ser obtido na matriz de coeficientes de cargas fatoriais.

A escolha dos fatores também representa um aspecto importante na análise fatorial. De acordo com Hair et al. (2009), se o número de fatores for muito reduzido, estruturas importantes nos dados podem ser omitidas; por outro lado, se o número de fatores for excessivo, fica mais difícil interpretá-los. O presente trabalho utilizou o critério desenvolvido por Kaiser (1958), conhecido como critério da raiz latente ou critério de Kaiser. Por meio desse critério apenas os fatores com autovalores acima de 1 são considerados. Como os dados foram padronizados, cada variável tem média 0 e variância igual a 1, e corresponde a quanto o fator consegue explicar da variância total. Quando esse critério é adotado, os fatores que têm um grau de explicação da variância total menor que a variância de uma variável, que é igual a 1, são descartados, por serem considerados não significativos. Os fatores constituem uma combinação linear das variáveis originais padronizadas, ou seja:

$$
\begin{aligned}
& F_{j}=\omega_{j I} X_{1}+\omega_{j 2} X_{2}+\omega j_{3} X_{3}+\ldots+\omega_{j l} X_{i} \\
& F_{j}=\sum_{i}^{\stackrel{\mathrm{I}}{=}} 1 \omega_{j i} X_{\mathrm{i}}
\end{aligned}
$$

em que:

$F_{j}=$ fator $\mathrm{j}$ comum.

$\omega_{i j}=$ os coeficientes de escores fatoriais.

$X_{i}=$ cada variável i original padronizada.

Para verificar se os dados utilizados são adequados para aplicar o método de análise fatorial foram empregados dois testes: o critério de Kaiser-Meyer-Olkin (KMO) e o teste de esfericidade de Bartlett. O primeiro observa se a matriz de correlação inversa é próxima da matriz diagonal e consiste em comparar os valores dos coeficientes de correlação linear observados com os valores dos coeficientes de correlação parcial. Para interpretação do critério de KMO, os valores vão variar de 0 a 1, pois pequenos valores de KMO indicam que o uso da análise fatorial não é adequado, e quanto mais próximo de 1, mais adequada é a aplicação da análise fatorial nos dados, sendo que valores entre 0,8 e 1 são considerados adequados.

Por sua vez, o teste de esfericidade de Bartlett considera como hipótese nula que a matriz de correlação entre as variáveis é uma identidade ou que as correlações entre variáveis são nulas. Assim, se essa hipótese for rejeitada, a análise fatorial pode ser aplicada. Para Hair et al. (2009), a hipótese nula será rejeitada se a correlação entre pelo menos algumas variáveis forem significativas.

Outro elemento para reforçar a adequação dos resultados é verificar a confiabilidade dos fatores. Para isso, Cortina (1993) destaca a utilização do alfa de Cronbach, o qual é influenciado tanto pelo valor das correlações dos itens quanto pelo número de itens avaliados. Por isso, fatores com poucos itens tendem a apresentar alfas de Cronbach menores, enquanto uma matriz com elevadas correlações entre cada item tende a apresentar um valor elevado do alfa. 
Após realizar a análise fatorial e testar a adequação do método pelo teste KMO e Bartlett, verificou-se o grau de desenvolvimento rural de cada estado brasileiro por meio dos escores fatoriais, ou seja, dos valores dos fatores para cada uma das 27 observações (26 estados mais o Distrito Federal). Pela fórmula 3 calculou-se o IB de desenvolvimento rural, por meio da média dos fatores (ponderada pela variância) pertencentes a cada observação.

Como procedeu-se à análise fatorial pelo método de componentes principais (que faz com que o primeiro fator contenha o maior percentual de explicação da variância total das variáveis da amostra, que o segundo fator contenha o segundo maior percentual, e assim por diante), a ponderação pela proporção de explicação da variância total exprime a importância relativa de cada fator. Registre-se que outros estudos aplicaram o mesmo procedimento, a exemplo de Cunha et al. (2005), Melo e Parré (2007), Monteiro e Pinheiro (2004), Silva et al. (2006) e Stege e Parré (2013).

$$
I B=\frac{\sum_{i=1}^{4}\left(w_{i} F_{i}\right)}{\sum_{i=1}^{4} w_{i}}
$$

em que:

$I B=$ índice bruto (média ponderada dos escores fatoriais).

$w_{i}=$ proporção da variância explicada por cada fator.

$F_{i}=$ escores fatoriais.

Após o cálculo do IB, calculou-se o IDR por meio da interpolação, considerando o maior valor de IB como 100 e o menor como 0, para cada estado brasileiro, atribuindo-lhes uma ordenação. Foram considerados três graus de desenvolvimento de acordo com o valor do IDR: alto desenvolvimento (IDR $\geq 0,8)$; médio desenvolvimento $(0,80>\operatorname{IDR} \geq 0,40)$; e baixo desenvolvimento (IDR $<0,4)$.

Os resultados obtidos foram mapeados de acordo com os três grupos de desenvolvimento para melhor visualização geográfica das condições socioeconômicas nas áreas rurais dos estados brasileiros. Assim, a análise dos indicadores sociais por meio de mapas facilita a identificação das localidades que contemplam níveis de desenvolvimento rural: elevado, médio e baixo.

\section{Resultados}

Os resultados da análise fatorial estão apresentados na Tabela 2, com as cargas fatoriais, as comunalidades associadas a cada um dos fatores estimados, os valores das raízes características, o percentual explicado por fator, os testes de adequação à análise fatorial e o teste de confiabilidade de cada fator. Os resultados mostram que, após a rotação ortogonal, foram extraídos quatro fatores (F1, F2, F3 e F4) com raiz característica maior que a unidade e que sintetizam as informações contidas nas 15 variáveis originais. 
Tabela 2. Cargas fatoriais dos dois fatores e comunalidades na análise fatorial dos indicadores socioeconômicos no meio rural dos estados brasileiros em 2005 e 2015.

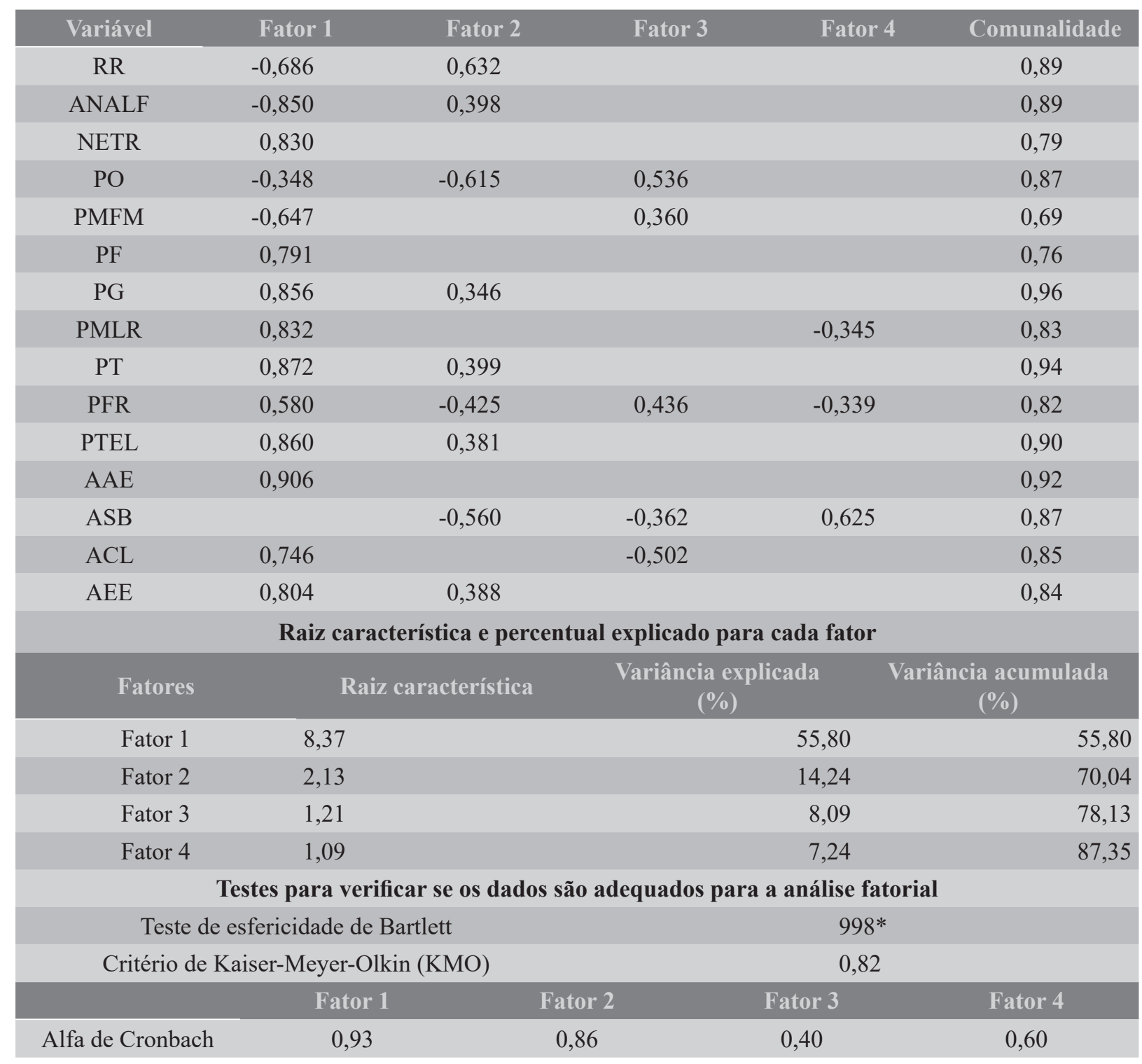

Fonte: Elaborado pelos autores.

Nota: *Significativo a $1 \%$.

Verifica-se que os fatores F1, F2, F3 e F4 respondem, respectivamente, por 55,80\%, 14,25\%, $8,09 \%$ e 7,24\% da variância total das variáveis utilizadas e, em conjunto, explicam $87,35 \%$ da variância total dos dados. O valor do teste Kaiser-Meyer-Olkin (KMO) foi de 0,82 e o teste de esfericidade de Bartlett foi significativo a 1\%. Esses resultados indicam que a utilização da análise fatorial é adequada para as variáveis utilizadas.

O teste de confiabilidade, a partir do Alfa de Cronbach, mostrou valores elevados para os fatores F1 e F2, sendo respectivamente 0,93 e 0,86. Para os fatores F3 e F4, os valores foram menores, uma vez que o número de observações associado a eles foi menor.

Cabe agora interpretar os fatores de desenvolvimento resultante da análise de componentes principais, ou seja, identificar as variáveis que possuem maior correlação com cada fator; cabe ainda destacar que foram consideradas para caracterização dos fatores as variáveis que apresenta- 
ram valores acima de 0,50 . Na Tabela 2 apresentam-se as cargas fatoriais e as comunalidades associadas a cada um dos quatro fatores estimados após a rotação ortogonal pelo método Varimax, destacando-se as maiores cargas fatoriais correspondentes aos indicadores utilizados.

A partir dos resultados obtidos é possível observar os fatores que apresentaram comunalidade acima de 0,8 e que representam de maneira satisfatória a variabilidade das variáveis. São eles: percentual de pessoas que recebem valor igual ou inferior a um salário mínimo, taxa de analfabetismo, percentual de ocupados, percentual de pessoas que residem em domicílios que possuem bens duráveis, como geladeira, máquina de lavar roupa, televisão, freezer e telefone. Também estão em destaque quatro variáveis que representam a infraestrutura domiciliar: água encanada, energia elétrica, coleta de lixo e saneamento básico.

No tocante ao fator 1, este possui correlação positiva com o nível educacional dos trabalhadores, com as variáveis que representam acesso a bens duráveis, como fogão, geladeira, máquina de lavar roupa, televisão, freezer e telefone. Além de três variáveis que refletem as condições de infraestrutura urbana, como acesso a água encanada, coleta de lixo e energia elétrica. Por outro lado, as variáveis que apresentam relação negativa com o fator 1 são: percentual de pessoas que recebem valor igual ou menor que um salário mínimo, taxa de analfabetismo, percentual de crianças que nasceram mortas e taxa de ocupados.

Desse modo, é possível inferir que o fator 1 pode ser caracterizado como de elevado desenvolvimento, uma vez que destaca as relações negativas com variáveis como baixa renda, analfabetismo e crianças que morreram ao nascer e, ao mesmo tempo, realça a situação econômica representada pelo acesso a infraestrutura urbana e a bens duráveis. A relação observada com a taxa de ocupação na área rural está associada negativamente com o fator, o que não era esperado, porém o valor de 0,35 indica baixo impacto sobre o fator 1 .

Por sua vez, o fator 2 está correlacionado positivamente com a renda igual ou abaixo de um salário mínimo. Diferentemente, a relação com a taxa de ocupação e percentual de moradores em domicílios que possuem saneamento básico foram negativos. Como o fator apresenta relação positiva com variáveis que são consideradas ruins no sentido de desenvolvimento e apresenta relação negativa com um importante item que caracteriza o desenvolvimento, o fator 2 pode ser considerado de baixo desenvolvimento.

Quanto ao fator 3, observa-se relação positiva com a variável percentual de ocupados. Diferentemente, a variável de infraestrutura que corresponde às pessoas em residências que têm acesso a coleta de lixo foi negativa. Nesse caso é possível verificar que o fator 3 está associado a poucas variáveis e que apresenta situações divergentes, representando uma situação de baixo para médio desenvolvimento.

Por último, o fator 4 está associado a três variáveis, sendo que a relação positiva se dá com o saneamento básico; e a negativa, com o acesso a máquina de lavar roupa e freezer, porém, com essas duas últimas, os valores são muito baixos: - 0,345 e - $-0,339$. Como o maior valor está relacionado a um aspecto positivo do desenvolvimento socioeconômico é possível inferir que o fator 4 reflete o acesso ao saneamento. 
Uma vez discutidas as informações sobre os resultados da análise fatorial, a etapa seguinte consiste na construção do índice para mensurar o nível de desenvolvimento socioeconômico nas áreas rurais dos estados brasileiros nos anos de 2005 e 2015, o que permite uma análise das mudanças no período considerado. Buscando compatibilizar tanto a homogeneidade entre os estados quanto sua diversidade, três níveis de desenvolvimento foram considerados: alto, médio e baixo.

Os resultados foram apresentados em mapas, para melhorar a visualização na dinâmica do desenvolvimento econômico e social na área rural dos estados brasileiros, e podem ser averiguados com base na Figura 1, que permite observar a distribuição geográfica por nível de desenvolvimento por estado selecionado e para os 2 anos analisados. Estão destacados em vermelho os estados com baixo nível de desenvolvimento, os que apresentaram desenvolvimento médio estão realçados na cor verde e os denotados em azul apresentam elevado nível de desenvolvimento.

No ano de 2005 foram registrados nove estados caracterizados com elevado desenvolvimento rural, a saber: São Paulo, Rio de Janeiro, Espírito Santo, Goiás, Distrito Federal, Mato Grosso do Sul, Paraná, Santa Catarina e Rio Grande do Sul. Todos esses estados apresentaram relação positiva com o fator 1, que está associado a variáveis que representam aspectos positivos na vida da população, como acesso a bens duráveis e à infraestrutura urbana, que consequentemente contribuem para melhorar o indicador de desenvolvimento social e econômico. Além do mais, quase todos (exceto Rio de Janeiro e Espírito Santo) estão alinhados positivamente com o fator 2, que incorpora aspectos positivos (como acesso a alguns bens duráveis e educação dos trabalhadores), mas também negativos, como percentual de pessoas com renda igual ou menor que o mínimo e taxa de analfabetismo, dois problemas que afligem a população rural e que devem ser combatidos com políticas públicas focadas na educação e ações que gerem emprego e renda (Anexo I).

Com relação aos de médio desenvolvimento foram observados dez estados: Minas Gerais, Mato Grosso, Rondônia, Roraima, Amapá, Ceará, Rio Grande do Norte, Paraíba, Pernambuco e Sergipe. Esse grupo apresenta dois estados, Minas Gerais e Rondônia, que estão positivamente relacionados com o fator 1, porém o valor é muito baixo. Já os outros apresentaram relação negativa com o fator 1, sugerindo assim que o percentual de pessoas com acesso a bens duráveis e à infraestrutura urbana está aquém do esperado, o que pode ser resultado de renda insuficiente para adquirir bens e contratar serviços como água e esgoto (Anexo I).

Os estados considerados de baixo desenvolvimento rural foram: Bahia, Alagoas, Piauí, Maranhão, Pará, Amazonas, Acre e Tocantins. Esses estados apresentam relação negativa com o fator 1 e com valores elevados (Anexo I). Isso pode demostrar um baixo percentual de pessoas vivendo na área rural com acesso a bens duráveis e com infraestrutura urbana; além do mais, como o fator está relacionado negativamente com o percentual de pessoas que recebem uma renda muito baixa, isso pode indicar insuficiência de renda para as famílias e elevada taxa de analfabetismo.

Já no mapa referente ao ano de 2015, o número de estados considerados de elevado desenvolvimento aumentou para 16, dos quais 9 já compunham esse grupo em 2005: São Paulo, Rio de Janeiro, Espírito Santo, Goiás, Distrito Federal, Mato Grosso do Sul, Paraná, Santa Catarina e Rio Grande do Sul. Sendo que, após uma década, outros sete apresentaram evolução nos indicadores socioeconômicos, sendo eles: Minas Gerais, Mato Grosso, Rondônia, Maranhão, Rio Grande do 
Norte, Paraíba e Sergipe. Nota-se que a evolução se deu nas variáveis que representam acesso a bens duráveis e em algumas associadas à infraestrutura básica, como água e energia elétrica. Da mesma forma que o observado anteriormente, os estados aqui destacados apresentaram elevada associação com o fator 1 (Anexo II).

O grupo que contempla as unidades federativas com baixo desenvolvimento rural apresentou, no ano de 2015, oito estados, dois a menos do que o observado em 2005. Registre-se que Roraima, Ceará, Pernambuco e Alagoas foram considerados de médio desenvolvimento em 2005; Pará, Tocantins, Piauí e Bahia melhoraram de condição. Um elemento importante que auxiliou esses estados a alcançarem um nível melhor de desenvolvimento pode estar no aumento da renda e na redução do analfabetismo, além da ampliação do consumo de bens duráveis e de melhoria na infraestrutura do domicílio, dada a associação com o fator 1 (Anexo II).

Diferentemente, permaneceram caracterizados como de baixo desenvolvimento: Acre, Amazonas e Amapá. Os fatores apresentados no Anexo II demostram que os três estados apresentam relação negativa com o fator 1 . Sendo assim, as evidências sinalizam que a população rural dessas unidades da federação ainda carece de acesso a bens duráveis essenciais, que há um baixo percentual de domicílios com infraestrutura básica aquém do ideal, o que compromete a qualidade de vida desses cidadãos com impactos sobre o indicador de desenvolvimento rural.

Figura 1. Mapa de desenvolvimento socioeconômico na área rural dos estados brasileiros, 2005 e 2015.

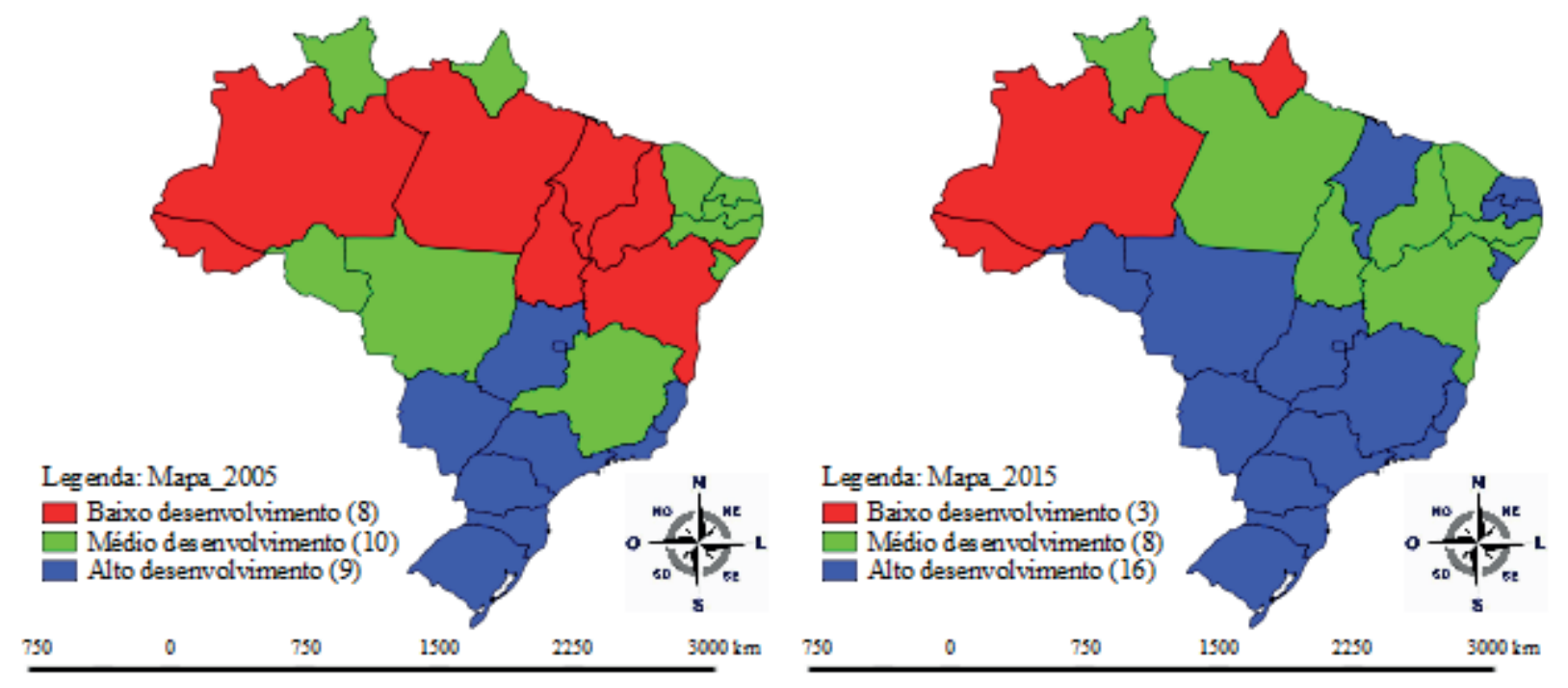

Fonte: Elaborado pelos autores com base em dados do IBGE (2020).

Os resultados apresentados neste estudo reforçam que houve uma melhora nas condições de vida da população rural dos estados brasileiros entre 2005 e 2015. Porém é importante ressaltar a necessidade de avançar em políticas públicas que incluam mais famílias com acesso a renda, para aumentar a quantidade de residências com bens duráveis, como, por exemplo, o Pronaf (BRAMBILLA; MICHELLON, 2019). Outro ponto é a infraestrutura domiciliar, que, nesse caso, foi mensurada pelos percentuais de pessoas que têm acesso a água encanada, a esgotamento sanitário, coleta de lixo e energia elétrica. Os aspectos voltados à educação também devem estar na pauta dos governos das três esferas, pois ainda é baixo o percentual de trabalhadores no meio 
rural que possuem uma significativa quantidade de anos de estudo, ao mesmo tempo em que há uma parcela considerável de analfabetos.

\section{Considerações finais}

O presente artigo objetivou criar um indicador que demonstrasse o desenvolvimento no meio rural nos estados brasileiros em 2005 e 2015. Para tanto foi aplicada a análise fatorial em 15 variáveis que representam a renda, a educação, a saúde, o nível educacional dos trabalhadores, a taxa de ocupação, o acesso a bens duráveis e a infraestrutura. Os testes de KMO e Bartlett mostraram que a aplicação do método de análise fatorial foi adequada aos dados. Sendo assim, utilizou-se o resultado dos escores fatoriais de cada estado e a variância explicada dos fatores para construção de um indicador que mostrasse quais estados possuíam melhores condições de vida para a população. Na sequência foi realizada a interpolação para criar uma classificação de 0 a 100, que representava a posição do estado no que se refere às condições socioeconômicas da população rural.

Pela média das variáveis foi possível verificar evolução em grande parte dos indicadores sociais e econômicos associados à população rural, demostrando que houve evolução no que tange à educação e saúde. O percentual de pessoas que recebe valor igual ou menor que um salário mínimo apresentou leve aumento, fato este que pode estar associado à crise econômica brasileira de 2015, quando o PIB real diminuiu em 3,5\% (IBGE, 2019). As variáveis que mensuram o acesso a bens duráveis e à infraestrutura dos domicílios também apresentaram forte crescimento, sendo que, em alguns casos, ultrapassou os $90 \%$, é o caso do percentual de pessoas em residências onde há fogão, geladeira, televisão e energia elétrica.

Com base no IDR ficaram evidentes as disparidades entre as regiões no que concerne à qualidade de vida dos cidadãos, uma vez que quase todos os estados das regiões Sul e Sudeste (exceto Minas Gerais, em 2005) apresentaram elevado desenvolvimento, tanto em 2005 quanto em 2015. Entretanto, é notório o crescimento no percentual de pessoas que estão conseguindo aumentar o consumo de bens duráveis essenciais e com acesso a infraestrutura.

Esse resultado pode ser visto na mudança de grupos de grande parte dos estados que eram considerados de baixo desenvolvimento para os de médio ou elevado desenvolvimento. A melhora verificada não significa que as políticas regionais ou federais voltadas à população rural devam diminuir, ao contrário, é preciso estar atento às necessidades que não estão sendo atendidas e ampliar as ações de combate à pobreza a partir da geração de emprego e renda, voltadas à educação, à melhoria da infraestrutura e ao combate às desigualdades entre as regiões.

Indubitavelmente, este artigo não esgota a discussão acerca do tema pobreza rural, principalmente por se tratar do caso brasileiro. Entretanto, diante dos resultados encontrados e dos apontamentos observados na revisão de literatura, alguns fatores são importantes para a redução da pobreza rural, a saber: 1) aumento da renda per capita da população rural combinada com uma melhor distribuição da renda; 2) acesso a crédito rural para aquisição dos insumos de produção, especialmente máquinas, equipamentos e melhores instalações, seja de moradia rural ou de armazenagem da produção; 3) ampliação da escolaridade da população rural; 4) políticas públicas direcionadas para o estímulo da produção, respeitando os aspectos regionais; 5) manutenção de 
uma ampla rede de proteção social, tendo-se uma renda mínima e acesso aos serviços básicos de saúde; e 6) estímulo à pluralidade produtiva, especialmente a produtos de maior valor agregado, dentro de uma estrutura de agricultura familiar.

\section{Referências}

BATISTA, H. R.; NEDER, H. D. Efeitos do Pronaf sobre a pobreza rural no Brasil (2001-2009). Revista de Economia e Sociologia Rural, v. 52, p. 147-166, 2014.

BEBBINGTON, A. Capitais e capacidades: uma estrutura para analisar a viabilidade camponesa, meios de subsistência rurais e pobreza. World Development, v. 27, n. 12, p. 2021-2044, 1999.

BORJA, P. C. Política pública de saneamento básico: uma análise da recente experiência brasileira. Saúde e Sociedade, v. 23, n. 2, p. 432-447, 2014.

BRAMBILLA, M. A.; MICHELLON, E. Focalização do PRONAF na Região Sul do Brasil. Revista de Economia, v. 40, n. 72, p. 115-133, 2019.

CARDOSO, D. F.; RIBEIRO, L. C. S. Índice relativo de qualidade de vida para os municípios de Minas Gerais. Planejamento e Políticas Públicas, n. 45, jul./dez. 2015.

COLMAN, D.; NIXSON, F. Desenvolvimento econômico: uma perspectiva moderna. São Paulo: Universidade de São Paulo, 1981.

CORRAR, L. J.; PAULO, E.; DIAS FILHO, J. M. Análise multivariada: para cursos de administração, ciências contábeis e economia. São Paulo: Atlas, 2012.

CORTINA, J. M. What is coefficient alpha? An examination of theory and applications. Journal of Applied Psychology, v. 78, n. 1, p. 98-104, 1993.

CUNHA, N. R. S.; LIMA, J. E.; MOURA, L. R. C. Degradação ambiental nos estados de Goiás e Tocantins. In: CONGRESSO DA SOCIEDADE BRASILEIRA DE ECONOMIA, ADMINISTRAÇÃO E SOCIEOLOGIA RURAL, 43., 2005, Ribeirão Preto. Anais... Ribeirão Preto: Sober, 2005.

DEL GROSSI, M. E. Evolução das ocupações não-agrícolas no meio rural brasileiro: 1981-1995. 1999. 229 f. Tese (Doutorado em Ciências Econômicas) - Instituto de Economia, Universidade Estadual de Campinas, Campinas.

DIAS, C. A. Estratégia do planejamento nacional: desafios do desenvolvimento. Desafios do Desenvolvimento, Brasília, DF, ano 8, n. 69, p. 58-64, 2011.

FEDERAÇÃO DAS INDÚSTRIAS DO RIO DE JANEIRO - FIRJAN. Índice da Firjan de desenvolvimento municipal (IFDM). Rio de Janeiro, 2016. Disponível em: www.firjan.org.br/ifdm. Acesso em: 19 fev. 2020.

FUNDAÇÃO DE ECONOMIA E ESTATÍSTICA DO RIO GRANDE DO SUL - FEE. Índice de desenvolvimento socioeconômico (IDS). Porto Alegre, 2020. Disponível em: www.fee.rs.gov.br/indicadores/ indice-de-desenvolvimento-socioeconomico. Acesso em: 18 fev. 2020.

GLASER, M. Inter-relações entre ecossistema manguezal, a economia local e a sustentabilidade social no estuário do Caeté. Norte do Brasil, p. 38-41, 2005.

GRISA, C.; SCHNEIDER, S. Políticas públicas de desenvolvimento rural no Brasil. Porto Alegre: UFRGS, 2015. 624 p. 
HAIR, J. F. J. et al. Análise multivariada de dados. 6. ed. Porto Alegre: Bookman, 2009.

HOFFMANN, R. Componentes principais e análise fatorial. Piracicaba: ESALQ/USP, 1999. 40 p. (Série didática, n. 90).

HOFFMANN, R.; KAGEYAMA, A. A. Modernização da agricultura e distribuição de renda no Brasil. Pesquisa e Planejamento Econômico, v. 15, n. 1, p. 171-208, 1985.

INSTITUTO BRASILEIRO DE GEOGRAFIA E ESTATÍSTICA - IBGE. Pesquisa Nacional de Amostra por Domicílio (PNAD), 2005 e 2015. Brasília, DF, 2015. Disponível em: https://www.ibge.gov.br/estatisticas/sociais/rendimento-despesa-e-consumo/9127-pesquisa-nacional-por-amostra-de-domicilios.ht$\mathrm{ml}$ ?=\&t=o-que-e. Acesso em: 20 fev. 2020.

INSTITUTO BRASILEIRO DE GEOGRAFIA E ESTATÍSTICA - IBGE. Sistema de Contas Nacionais Trimestrais - SCNT. Brasília, DF, 2019. Disponível em: https://www.ibge.gov.br/explica/pib.php. Acesso em: 20 dez. 2019.

INSTITUTO DE PESQUISA ECONÔMICA APLICADA - IPEA. Índice de Desenvolvimento Humano Municipal Brasileiro. Brasília, DF: PNUD, IPEA, 2013.

INSTITUTO PARANAENSE DE DESENVOLVIMENTO ECONÔMICO E SOCIAL - IPARDES. Índice IPARDES de desenvolvimento municipal (IPDM). Curitiba, 2016. Disponível em: www.ipardes.gov.br/ipdm. Acesso em: 25 fev. 2020.

JONHSON, R. A.; WICHERN, D. W. Applied multivariate statistical analysis. 6. ed. New Jersey: Pearson, 2007.

JORGE, M. A. et al. Cálculo e implementação do índice de desenvolvimento da gestão municipal (IDGM) do município de Itabaiana/SE. Planejamento e Políticas Públicas, Brasília, v. 34, p. 9-34, 2010.

KAISER, H. F. The varimaxcriterion for analyticrotation in factoranalysis. Psychometrika, v. 33, n. 3, p. 187-200, 1958.

LAMB, D.; ERSKINE, P. D.; PARROTTA, J. A. Restoration of degraded tropical forest landscapes. Science, v. 310, n. 5754, p. 1628-1632, 2005.

LIMA, V. M. A.; CALDARELLI, C. E.; CAMARA, M. R. G. Análise do desenvolvimento municipal paranaense: uma abordagem espacial para a década de 2000. Revista Economia e Desenvolvimento, Santa Maria, v. 26, n. 1, p. 1-19, 2014.

MANKIW, G. Introdução à economia. 6. ed. São Paulo: Cengage Learning, 2016.

MARCONATO, M.; CUNHA, M. S. Análise do desenvolvimento multidimensional dos municípios brasileiros nos anos de 2000 e 2010. Revista Econômica do Nordeste, v. 47, n. 2, 2016.

MATTOS, E. J. de; BAGOLIN, I. P. Reducing poverty and food insecurity in rural Brazil: the impact of the Zero Hunger Program. EuroChoices, v. 16, n. 1, p. 43-49, 2017.

MATTOS, E. J. de; SANTOS, A. M. A. dos. Pobreza rural na região Nordeste do Brasil: uma perspectiva além da renda. Revista Espacios, Caracas, v. 38, n. 14, p. 8-24, 2017.

MELO, C. O.; PARRÉ, J. L. Índice de desenvolvimento rural dos municípios paranaenses: determinantes e hierarquização. Revista de Economia e Sociologia Rural, Rio de Janeiro, v. 45, n. 2, p. 329-365, 2007.

MONTEIRO, V. P.; PINHEIRO, J. C. Critério para implantação de tecnologias de suprimentos de água potável em municípios cearenses afetados pelo alto teor de sal. Revista de Economia e Sociologia Rural, Rio de Janeiro, v. 42, n. 2, p. 365-387, 2004. 
NASCIMENTO, C. A. do. Pluriatividade e política pública: o caso do Sul do Brasil. Brazilian Journal of Political Economy, v. 27, n. 3, p. 452-471, 2007.

OLIVEIRA, E. N.; SILVA, N. R. Desenvolvimento socioeconômico das microrregiões do Nordeste brasileiro. In: ENCONTRO NACIONAL DA ASSOCIAÇÃO BRASILEIRA DE ESTUDOS REGIONAIS E URBANOS, 10., 2012, Recife. Anais... Recife: Aber, 2012.

PINTO, C. V. S.; ROCHA, B. N.; PIRANI, N. C. Indicadores sociais e desenvolvimento rural: um estudo sobre o índice de desenvolvimento humano municipal rural no Brasil. Boletim Regional, Urbano e Ambiental, n. 18, p. 97-105, jan.-jun, 2018.

RAVALLION, M.; DATT, G. Why have some Indian states done better than others at reducing rural poverty? Washington, DC: The World Bank, 1999.

RODRIGUES, J. F. O rural e o urbano no Brasil: uma proposta de metodologia de classificação dos municípios. Análise Social, v. 211, n. 49, (2), 2014.

SEN, A. K. Desenvolvimento como liberdade. São Paulo: Companhia das Letras, 2000.

SICSÚ, J. Governos Lula: a era do consumo? Revista de Economia Política, v. 39, n. 1 (154), p. 128-151, 2019.

SILVA, G. H.; MELO, C. O.; ESPERANCINI, M. S. T. Regionalização do desenvolvimento econômico e social dos municípios da região oeste paranaense. In: ENCONTRO NACIONAL DA ASSOCIAÇÃO BRASILEIRA DE ESTUDOS REGIONAIS E URBANOS, 4., 2006, Foz do Iguaçu. Anais... Foz do Iguaçu: Aber, 2006.

STEGE, A. L.; PARRÉ, J. L. Fatores que determinam o desenvolvimento rural nas microrregiões do Brasil. Confins, v. 19, n. 19, 2013.

SUPERINTENDÊNCIA DE ESTUDOS ECONÔMICOS E SOCIAIS DA BAHIA - SEI. Índice de performance econômica e social dos municípios baianos. 2020. Disponível em: www.sei.ba.gov.br/ide/ids. Acesso em: 27 fev. 2020. 


\section{Anexos}

Anexo I - Fatores, índice bruto (IB), índice de desenvolvimento rural (IDR) e classificação dos estados por nível de desenvolvimento rural no ano de 2005

\begin{tabular}{|c|c|c|c|c|c|c|c|}
\hline Estados & Fator 1 & Fator 2 & Fator 3 & Fator 4 & IB & IDR & Classificação \\
\hline São Paulo & 0,44644 & 0,23786 & 0,75277 & 2,96866 & 0,65459 & 100,00 & 2 \\
\hline Distrito Federal & 0,30881 & 0,28883 & 0,97348 & 3,00470 & 0,59712 & 97,62 & 3 \\
\hline Rio Grande do Sul & 0,88111 & 0,52503 & $-2,11401$ & 1,56018 & 0,59539 & 97,55 & 4 \\
\hline Rio de Janeiro & 0,44050 & $-0,06910$ & 0,61214 & 2,41018 & 0,53881 & 95,20 & 5 \\
\hline Santa Catarina & 0,57432 & 0,99766 & $-1,52857$ & 1,23063 & 0,50127 & 93,64 & 6 \\
\hline Mato Grosso do Sul & 0,75028 & 0,33737 & $-1,21804$ & $-0,28511$ & 0,40701 & 89,73 & 7 \\
\hline Espírito Santo & 0,75038 & $-0,09778$ & $-1,43298$ & 0,67803 & 0,39579 & 89,27 & 8 \\
\hline Paraná & 0,38316 & 0,26710 & $-1,35668$ & 1,01788 & 0,25271 & 83,33 & 9 \\
\hline Goiás & 0,40069 & 0,16604 & $-0,80026$ & $-0,00894$ & 0,21297 & 81,69 & 10 \\
\hline Minas Gerais & 0,09208 & $-0,19458$ & $-1,27116$ & 0,10946 & $-0,08349$ & 69,39 & 11 \\
\hline Rondônia & 0,08428 & $-0,46380$ & $-1,92063$ & 0,76255 & $-0,13968$ & 67,06 & 12 \\
\hline Rio Grande do Norte & $-0,38900$ & $-1,06910$ & 0,93181 & 0,83695 & $-0,27328$ & 61,52 & 13 \\
\hline Mato Grosso & $-0,47452$ & 0,47439 & $-1,55301$ & $-0,56166$ & $-0,42584$ & 55,20 & 14 \\
\hline Sergipe & $-0,48063$ & $-0,78305$ & $-0,75290$ & 0,38228 & $-0,48370$ & 52,80 & 15 \\
\hline Paraíba & $-0,46797$ & $-0,93201$ & $-0,08214$ & $-0,17294$ & $-0,48379$ & 52,79 & 16 \\
\hline Amapá & $-1,28602$ & 1,29826 & $-0,36215$ & 0,19697 & $-0,64155$ & 46,25 & 17 \\
\hline Pernambuco & $-0,83036$ & $-0,82166$ & 0,11246 & $-0,14509$ & $-0,68142$ & 44,60 & 18 \\
\hline Ceará & $-0,94458$ & $-0,78034$ & 0,00964 & $-0,09133$ & $-0,75437$ & 41,57 & 19 \\
\hline Roraima & $-1,29067$ & 0,46413 & $-0,96946$ & 0,94982 & $-0,77746$ & 40,62 & 20 \\
\hline Bahia & $-1,20788$ & $-0,94183$ & $-0,03175$ & $-0,16557$ & $-0,96361$ & 32,90 & 21 \\
\hline Piauí & $-0,87803$ & $-1,78136$ & $-1,12957$ & $-0,33186$ & $-1,00625$ & 31,13 & 22 \\
\hline Alagoas & $-1,42234$ & $-1,11845$ & 1,03299 & $-0,07877$ & $-1,02495$ & 30,35 & 23 \\
\hline Tocantins & $-1,29907$ & $-0,35144$ & $-1,08498$ & $-0,71706$ & $-1,07133$ & 28,43 & 24 \\
\hline Pará & $-1,94627$ & $-0,09643$ & 0,10132 & 0,70717 & $-1,21854$ & 22,32 & 25 \\
\hline Amazonas & $-2,52755$ & 1,24017 & 0,39456 & $-0,01845$ & $-1,40921$ & 14,42 & 26 \\
\hline Acre & $-2,09120$ & $-0,32125$ & 0,02712 & $-0,17842$ & $-1,43291$ & 13,43 & 27 \\
\hline Maranhão & $-2,37282$ & $-0,91589$ & $-0,38291$ & $-0,20026$ & $-1,75688$ & 0,00 & \\
\hline
\end{tabular}

Fonte: Elaborado pelos autores com base em dados do IBGE (2020). 
Anexo II - Fatores, índice bruto (IB), índice de desenvolvimento rural (IDR) e classificação dos estados por nível de desenvolvimento rural no ano de 2015

\begin{tabular}{|c|c|c|c|c|c|c|c|}
\hline Estados & Fator 1 & Fator 2 & Fator 3 & Fator 4 & IB & IDR & Classificação \\
\hline São Paulo & 0,38989 & 1,35265 & 1,51704 & 0,84568 & 0,69600 & 100,00 & 2 \\
\hline Rio de Janeiro & 0,40155 & 0,63712 & 1,83134 & 1,68336 & 0,68509 & 99,20 & 3 \\
\hline Rio Grande do Sul & 0,79032 & 1,62174 & $-0,48781$ & $-0,79836$ & 0,67313 & 98,32 & 4 \\
\hline Santa Catarina & 0,53801 & 1,78935 & 0,62163 & $-0,63512$ & 0,65520 & 97,00 & 5 \\
\hline Espírito Santo & 0,86134 & 0,75517 & $-0,03172$ & $-0,37694$ & 0,65395 & 96,91 & 6 \\
\hline Distrito Federal & 0,34619 & 1,46307 & 1,88511 & $-0,07799$ & 0,64241 & 96,06 & 7 \\
\hline Paraná & 0,68822 & 1,22924 & 0,18205 & $-0,35124$ & 0,64234 & 96,05 & 8 \\
\hline Minas Gerais & 0,93028 & $-0,07566$ & $-0,03721$ & 0,28837 & 0,61631 & 94,14 & 9 \\
\hline Rondônia & 1,12555 & 0,34478 & $-0,75616$ & $-1,33020$ & 0,60866 & 93,57 & 10 \\
\hline Sergipe & 1,25191 & $-1,48119$ & 0,39213 & $-0,01206$ & 0,60726 & 93,47 & 11 \\
\hline Goiás & 0,70964 & 1,22199 & $-0,09138$ & $-0,78207$ & 0,59267 & 92,39 & 12 \\
\hline Mato Grosso do Sul & 0,83140 & 1,21131 & $-1,05897$ & $-0,91694$ & 0,56731 & 90,53 & 13 \\
\hline Rio Grande do Norte & 0,72314 & $-0,65854$ & 1,52829 & $-0,08488$ & 0,50043 & 85,61 & 14 \\
\hline Paraíba & 1,08460 & $-1,08309$ & 0,09224 & $-0,58208$ & 0,48756 & 84,66 & 15 \\
\hline Mato Grosso & 0,60152 & 1,12384 & $-0,29219$ & $-1,26964$ & 0,44524 & 81,54 & 16 \\
\hline Maranhão & 1,30396 & $-1,94112$ & $-0,09116$ & $-1,11420$ & 0,42527 & 80,07 & 17 \\
\hline Alagoas & 0,81976 & $-1,54382$ & 1,72256 & $-0,21143$ & 0,42358 & 79,95 & 18 \\
\hline Bahia & 0,91770 & $-1,21834$ & 0,47238 & $-0,27923$ & 0,41763 & 79,51 & 19 \\
\hline Tocantins & 0,68593 & $-0,02807$ & 0,06903 & $-0,93969$ & 0,37047 & 76,04 & 20 \\
\hline Ceará & 0,73398 & $-1,09190$ & 1,29850 & $-0,72497$ & 0,35915 & 75,21 & 21 \\
\hline Pernambuco & 0,67594 & $-1,07206$ & 0,91168 & $-0,10933$ & 0,34007 & 73,80 & 22 \\
\hline Piauí & 0,97320 & $-1,25884$ & $-0,38708$ & $-0,80622$ & 0,32098 & 72,40 & 23 \\
\hline Pará & 0,38623 & $-0,43945$ & 0,23414 & $-0,86398$ & 0,12804 & 58,20 & 24 \\
\hline Roraima & $-0,16827$ & 0,91867 & 0,44918 & $-1,33411$ & $-0,02729$ & 46,77 & 25 \\
\hline Amapá & $-0,86300$ & 1,79128 & 1,74752 & $-1,65452$ & $-0,23988$ & 31,12 & 26 \\
\hline Acre & $-0,69383$ & $-0,07452$ & 0,69725 & $-0,66614$ & $-0,45631$ & 15,19 & 27 \\
\hline Amazonas & $-1,24829$ & 0,94764 & 0,62453 & $-0,75606$ & $-0,66269$ & 0,00 & \\
\hline
\end{tabular}

Fonte: Elaborado pelos autores com base em dados do IBGE (2020). 